\title{
Base Pair: 28 Years of Sustained High School Biomedical Research Mentorship Driving Health Sciences Career Progression
}

\author{
Stephen Stray', Xiaoshan Gordy ${ }^{1}$, Donna Sullivan', Susan Bender², Cindy Cook ${ }^{3}$, Kathy McKone ${ }^{4}$, Jeff Stokes ${ }^{2}$, and \\ Rob Rockhold ${ }^{1}$ \\ ${ }^{1}$ University of Mississippi Medical Center, Jackson, MS; ' 2 Jackson Public School District, Jackson, MS; ${ }^{3}$ Raleigh High School, Raleigh, MS; and ${ }^{4}$ Co-Lin Community \\ College, Wesson, MS
}

Keywords: Mentorship, Biomedical Research, High School Students, High School Teachers, Academic Health Sciences Center, Science Identity, STEM

Publication Date: October 21, 2020

DOI: https://doi.org/10.15695/jstem/v3i3.05

\begin{abstract}
Base Pair is an ongoing (1992-present) collaboration between University of Mississippi Medical Center (UMMC) faculty mentors and Mississippi high school students and teachers. UMMC faculty and Base Pair teachers designed a course which has allowed curriculum innovations by teachers. The student component engages 15 trainees annually in laboratory experiences under direct faculty mentorship while receiving high school graduation credit. Students have a $100 \%$ high school graduation rate (vs. $\sim 88 \%$ nationally) and $99 \%$ college entrance. These students have co-authored/presented over 450 times in UMMC, state or national venues. Of 220 graduates, roughly 63\% are in/have completed post-baccalaureate training. Of these, at least 49 have gained a terminal degree in science or law, while another 35 students have attained a Master's degree. Over 100 teachers have been mentored in grant-writing exercises and curriculum development, resulting in over 159 applications for external funding of inquiry-based classroom activities of which 78\% were funded. Teachers have also implemented several innovative STEM curricula, reaching thousands more students. These include a student team-based competition that fuses citizen science and molecular biology to assess insect infection with Wolbachia bacteria. Base Pair bolsters student engagement, promotes STEM/health career advancement for students, and enhances teacher job satisfaction.
\end{abstract}

\section{INTRODUCTION}

The need to prepare students for and guide them into the national STEM career workforce remains critical (National Science Board, 2015). In Mississippi, the gap between educational preparedness and STEM career outcomes is particularly acute, where as few as $20 \%$ of 8 th grade students demonstrated science proficiency, and only $4.6 \%$ of students in high school scored 3 or higher on an advanced placement (AP) exam (National Science Foundation, 2020). In fact, the Mississippi Department of Education reports that only 37.4\% of students achieved the national college and career ready standard in 2019. Racial disparity further exacerbates these gaps, as evidenced by the fact that Black students received only $20.2 \%$ of the STEM undergraduate degrees awarded by this state's public colleges and universities, despite the fact that almost $40 \%$ of Mississippians are Black (Mississippi Institutes of Higher Learning, 2020). These factors combine to explain the finding that only $3.3 \%$ of Mississippians engage in a STEM occupation, the lowest rate by percentage of all occupations in the United States; the national rate being $6.2 \%$ (Fayer et al., 2017).

To address these needs, an institutional STEM pipeline program, Base Pair, was implemented to use individual mentorship at the high school level as the vehicle to advance entry of students into biomedical science/health care professions, enhance teacher professional development, and stimulate innovative curriculum development. Structured as a biomedical research mentorship program, Base Pair has now operated continuously since 1992, demonstrating almost three decades of sustainability. Delivered on the campus of the University of Mississippi Medical Center (UMMC), Base Pair has directly served 232 students and over 100 teachers. Conservatively assuming that each teacher 
engages one class of 30 students per year and continues for five years following participation in Base Pair activities, our indirect influence exceeds 15,000 students and has expanded geographically to influence high school science education across central Mississippi.

Base Pair was created to leverage the intellectual capital and technological capabilities of UMMC as a complement of efforts to provide cutting-edge science instruction in the Jackson Public School District (JPSD). This recognized a unique role for UMMC as the sole academic health sciences center for this state, in which goals of advancing science education and improving the health of the citizens of the state were seen as inextricably intertwined. Expanding this role through collaboration and specific partnership with the secondary school system, while logical in hindsight, was a significant innovation in 1991-92. In its inception, Base Pair was modelled loosely after the Rockefeller University Summer Science Research Program (https://www.rockefeller.edu/ outreach/lab-initiative/summer-science/), but with two key differences. The program occurs as an integral component of a high school curriculum, with students receiving Carnegie credit toward graduation from participation in the program. Furthermore, the research activities in UMMC laboratories occurred during the school day, rather than after-school or during the summer months. Significant development of Base Pair was facilitated by a series of awards from the Howard Hughes Medical Institute (HHMI) Precollege Science Education program between 1994 and 2012.

Within the JPSD, Murrah High School was chosen because it housed a magnet program, the Academic and Performing Arts Complex (APAC), which recruited highly engaged teachers and students. Moreover, Murrah was physically adjacent to the UMMC campus, which facilitated the movement of students to and from UMMC during the school day. The inaugural class of nine Murrah senior students was launched in academic year 1992-1993. At present, the Base Pair class consists of 15 students who engage in activities over a two-year (junior and senior year) period. Approximately half of each class are first-year juniors with the remainder being second-year seniors.

Working with the Mississippi Department of Education, a new course offering, entitled Biomedical Research, was developed and approved in 1994. This one semester course not only prepares students for the technologically advanced, sophisticated, and health-focused environment of the UMMC research endeavor, but also permits academic credentialing of the program. Biomedical Research was added to the Mississippi Science Framework and was thus made available to any public high school in the state. As amended in 2017, schools may offer Biomedical Research if they document commitment from a college or university to serve as an instructional partner. At present, nine schools in Mississippi offer the course.
Base Pair also encompasses teacher professional development, with high school teachers engaging in mentored research and curriculum development activities during summer periods. These activities, described in detail in a later section, have resulted in creation of several innovative high school curricula and research-based activities, including Student Oriented Academic Research (SOAR), a Rural Biomedical Initiative (RBI), and a Wolbachia Rodeo molecular biology-focused team competition. The Wolbachia Rodeo is a molecular biology-focused team competition in which high schools sponsor four to five students for participation in a one-day hands-on laboratory designed to extract DNA from insects, use PCR to amplify specific genes of the intracellular bacteria Wolbachia and submit positive samples to the Wolbachia project at Vanderbilt University. In addition, one Base Pair-trained teacher spearheaded the creation of a Health Academy in a high school in central Mississippi.

In analogy to the highly specific coupling of nucleotide base pairs in deoxyribonucleic acid, the appellation, Base Pair, was ultimately chosen to identify the partnership between UMMC and Murrah. This recognized the pairing of individual UMMC faculty research mentors with Murrah students and the close physical proximity of the Murrah campus with the UMMC campus. The term, Base Pair, further exemplified the ubiquitous use of contemporary molecular biology techniques within the laboratories of the mentors, activities that were not routinely taught in high school curricula at the onset of the program. A timeline of major events of Base Pair, including funding and the sequence of lead teachers at Murrah, is presented in Figure 1.

Individual mentorship, which has been defined by the

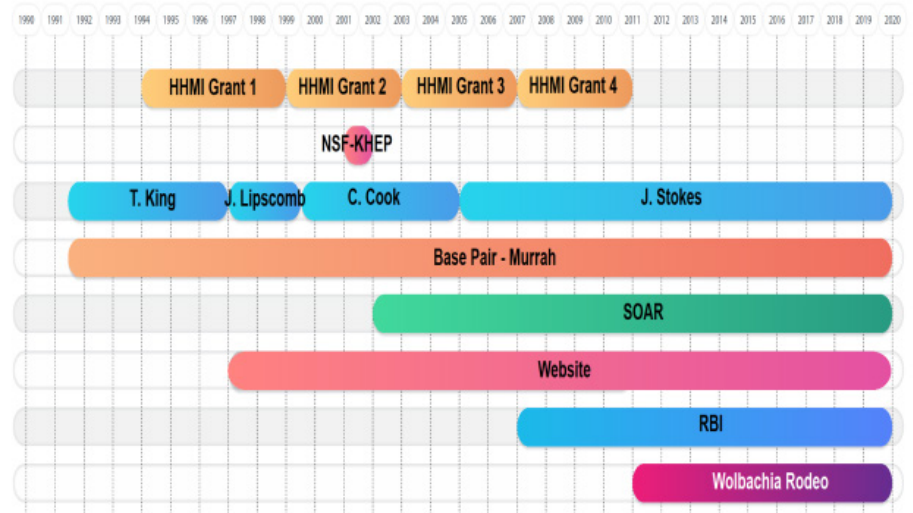

Figure 1. A graphical timeline of major events in the Base Pair program. The periods for and institutions providing significant funding for the programs are shown. The tenure and names of the four Murrah High School lead teachers are indicated. HHMI, Howard Hughes Medical Institute Precollege Science Education funding. KHEP, National Science Foundation K-12 Higher Education Partnership funding. SOAR, Student Oriented Academic Research. RBI, Rural Biomedical Initiative. The Base Pair website (Website) can be reached at https://www.umc.edu/Office $\% 20$ of $\% 20$ Academic $\% 20$ Affairs/For-Students/Academic $\% 20$ Outreach\%20Programs/Base\%20Pair/Base\%20Pair.html. 
National Academy of Sciences as "an activity in which science, technology, engineering, mathematics, and medicine (STEMM) professionals engage to help develop the next generation of STEMM professionals" (National Academy of Sciences, 2019), forms the central dogma of the Base Pair. Core features of mentorship: psychosocial/emotional support and role modeling, as well as career support to include career guidance, skill development, and professional sponsorship (National Academy of Sciences, 2019) are expressly embedded in the selection as, orientation for, and institutional support of UMMC Base Pair mentors.

Mentoring of pre-college students in university/academic health science center-level biomedical research, which equates to STEMM, is generating increased interest. Tai et al. (2006) clearly identified that career interest in STEM fields develops early, with pre-college experiences being a significant factor. Despite that, the specific influence of mentored pre-college research experiences is relatively poorly documented (Tai et al., 2017). VanMeter-Adams et al. (2014) examined a cohort of 131 students who participated in a mentored summer research program, of whom $59.1 \%$ engaged only while in high school. The remainder participated as undergraduate students $(32.2 \%)$ or participated both in high school and as an undergraduate (7.4\%). Most of the cohort $(65.5 \%)$ reported that extracurricular encounters initially ignited STEM interest. Of note was the finding that almost all $(92.6 \%)$ identified the mentored, hands-on laboratory activities as the key factor in sustaining their interest in STEM. Similarly, Findley-Van Nostrand and Pollenz (2017) showed that a mentored, summer pre-college laboratory experience sustained interest in STEM and was associated with significantly higher academic self-efficacy, science identity and expectations for STEM careers than those who had not participated in the experience. A large scale, quantitative analysis of 236,432 individuals examined the influence of mentored high school summer research laboratory apprenticeships (HSSRLA) on enrollment of medical students into $\mathrm{MD} / \mathrm{PhD}$ training programs (Tai et al., 2017). The high school-only cohort did not progress into $\mathrm{MD} / \mathrm{PhD}$ training to any greater degree than those with no laboratory apprenticeships. However, $\mathrm{MD} / \mathrm{PhD}$ progression was significantly higher among those who reported both a HSSRLA and a college laboratory research apprenticeship (CRLA), and a HSSRLA positively influenced progression into the CRLA. This was suggested to indicate that mentored high school research experiences serves the vital purpose of aiding students in determining whether to pursue a future STEM career. This is consistent with Base Pair experience as noted by two examples. One student, G.A., actually began Base Pair as one of the few high school freshmen to join and spent a full four years in UMMC mentored activities, publishing one full manuscript (Adams et al., 2001). He progressed to undergraduate education at Yale University, majored in art, and is now a suc- cessful film artist. A second student, A.J., spent two years in Base Pair activities, published a full manuscript (Summers et al., 1998), graduated medical school from Boston University, and is now a practicing physician in Mississippi. Mentoring in science and science education has most often been described in terms of a constructivist theoretical framework (Hudson, 2004), but of six common theoretical models for mentoring (National Academies of Science, 2019), the tripartite integration model of social influence (Estrada, 2011; Hernandez, 2018) best describes features of the Base Pair model. The tripartite model recognizes three key processes: compliance with research norms and rules, identification with a professional group, and internalization and sharing of group values. In Base Pair, students are given guidance and training to introduce the research focus and expectations of a mentor during and after the selection process; typically work closely with a research mentor and her/his laboratory group for an extended period of time; and through preparation, delivery, review and publication of scientific work, demonstrate internalization of professional scientific values. While no instrument has been applied to examine the creation of a unique science identify, the persistence, in high percentages, of Base Pair graduates into STEM educational pathways and STEMM careers strongly suggests that the program effectively inculcates identity as a professional scientist.

\section{PROGRAM ELEMENTS AND STRATEGIES}

Student Research Mentorship. Student research activities are managed as a collaboration among a lead teacher at Murrah High School, the Base Pair UMMC program director, and individual UMMC research mentors. Lead teachers are chosen based on recommendations from the Murrah Principal and approved by the program director. These individuals aid in student selection, teach a formal preparatory course in the first semester of the program at Murrah, facilitate effective communication between the Jackson Public School District and UMMC, and maintain regular oversight of student activities while students are engaged in UMMC laboratory activities. Base Pair students are selected as rising juniors in late spring through a process of formal application followed by review of teacher recommendations, academic records and a personal interview with the lead teacher and/or UMMC program director. During the following fall semester, newly selected students engage in a formal Mississippi Department of Education-approved class (Biomedical Research) taught by the lead teacher. Expectations for behavior, laboratory safety training, and proficiency with common research tools (micropipetting, use of analytical balances and a microcentrifuge, etc.) are addressed. Students gain familiarity with the basics of polymerase chain reaction (PCR) protocols. Field trips to UMMC are used to introduce students to biomedical information databases in- 
cluding PubMed and students use these to explore the primary literature publications of potential UMMC research mentors. In late fall, students interview with several of these mentors and generate a rank order preference that is used for pairing. As part of the Base Pair Biomedical Research preparatory course, each student is required to present their knowledge of the research of potential mentors to the class, ensuring that all students are fully aware of the research activities of the members of the mentor pool. The mentor pool itself consists of 20-30 faculty, depending on individual availability. It is common for students to be paired with their top-ranked faculty member, but both mentor and student must agree to the pairing. Most mentors are highly experienced with the Base Pair program and readily incorporate new students into their research routines. New mentors are interviewed by the program director and indoctrinated in the expectations for the mentorship. Students begin the research experience with the beginning of the spring semester, spending the last full 90 -minute period of the day at UMMC, five days/week until the end of the school year. Typically, in this spring semester, mentors engage students as full members of their research team. This includes orientation to laboratory processes, further safety training, and design of a research project for the student. In general, that project is a subset of efforts underway in that laboratory and permits the student to experience authentic research even within the time constraint of only about one hour/day in the UMMC laboratory. An overwhelming majority of students return in the fall of their senior year, when they spend both semesters in the research activity begun in the junior year. The lead teacher provides opportunities for incoming juniors to meet, interview and learn from the members of the senior class. Students and mentors are encouraged to prepare, submit and present the students' research in formal scientific settings. Senior students will develop and present their research in a professional scientific forum at least twice, once at the annual UMMC School of Health Related Professions Research Day as a faculty-judged, poster competition, and again at an annual statewide meeting of the Mississippi Academy of Sciences. This latter presentation can be as a poster or as an oral presentation. Junior students typically present only an overview of the concept for their proposed research effort at the annual UMMC School of Health Related Professions Research Day poster competition. These presentations serve as the primary outcome measure for Base Pair (see Program Outcomes below) and specifically inculcate students into the professional scientific community, cementing an important element of science identity.

Teacher Professional Development. Over 100 high school teachers have been recruited to participate in either summer-long (8-10 weeks), full-time research internships in mentors' laboratories (1992-1998) or in more structured workshops of from four to six weeks in duration (19992013). The internships engaged roughly a dozen teachers in focused generation of new research data while the workshops, which engaged 6-12 teachers/workshop, have focused on pedagogy and curriculum development. The majority of teachers were trained during the 18 years of HHMI funding in the workshops, which focused on using original research, case studies, and literature in which science is featured to generate student interest and advancement within the classroom. In the past several years, best practices in the design and use of the flipped learning/classroom model, and gaining familiarity with molecular laboratory skills for classroom use, have been addressed in the curriculum. All are introduced to the Base Pair student training model and the Biomedical Research course. Teachers are specifically introduced to grant-writing and, in the longer duration workshops, have been challenged to complete a small grant application to an external funding agency during the workshop. This grant-writing experience has proven to be extremely productive for some teachers (see Program Outcomes below). Informal assessment, in effect implementation analysis, has followed each iteration of the teacher workshops. Notable changes as a result of participant input have included reduction in the duration of the workshops, from what was initially eight weeks down to four by the end of the period of HHMI funding. Generally, this reflected increased demands on teacher time from school districts during the summer period. In addition, an initial focus on reading and discussion of literature about science using the Carl Djerassi tetralogy (Cantor's Dilemma, etc.) was removed due to teacher concerns about content. A cadre of 6-8 teachers have returned for multiple trainings and of these, several of these master teachers have created and implemented innovative new high school science curricula. These include the Student Oriented Academic Research (SOAR) program, the Rural Biomedical Initiative (RBI), the Wolbachia Rodeo, and the introduction of a Health Academy. Teachers from private schools also have been involved in Base Pair workshops. The experiences of one such teacher stimulated a \$5 million science classroom renovation project. Another led her students to create an experiment that was selected to be conducted in the International Space Station (Student Spaceflight Experiments Program; Bradley-Phillips, 2014).

SOAR Program. A National Science Foundation K-12 Higher Education Partnership (KHEP) award led to an alliance between UMMC, the JPSD and Tougaloo College, a Jackson area Historically Black College (HBCU). As a direct result, the SOAR program was created by a teacher at the JPSD Jim Hill High School. An under-resourced, urban, inner-city school, Jim Hill has a 100\% free and reduced lunch population and serves a majority Black student enrollment. A two to three-year curriculum, SOAR brings the excitement 
of science research into the classroom with an explicit focus on production of high-quality science fair projects by junior and senior students. Students remain with a single teacher across 10th-12th grade courses; Zoology 1 and 2 in the 10th; either Zoology 1 and 2 in the 10th or Microbiology and Genetics in the 11th; and Microbiology and Genetics in the 12th. Each student is required to develop a project and receives academic credit for doing so. Throughout the course sequence, the evidence of success with student projects and the value gained in terms of progression into higher education and monetary awards/scholarships is emphasized. Both after school and Saturday sessions are scheduled. The SOAR lead teacher reviews projects to ensure that all necessary supplies and equipment are available from accessible sources (grocery stores, big box stores) and are in line with the resources of each student. This is a teacher-intensive activity but has been well supported by the administration at Jim Hill High School.

RBI. Created by a former Base Pair lead teacher, the RBI curriculum is focused specifically on under-resourced rural high schools, often serving small communities. It exposes students to basics of biomedical research and is an adaptation of the curriculum used in Biomedical Research at Murrah, but without the opportunity to engage in mentored medical center laboratory experiences. Rather, it uses the structure of Dual Enrollment Biology, AP Biology, and most recently Project Lead The Way courses, to present biomedical research concepts, educational pathways and career opportunities to students who are otherwise unlikely to be introduced to such. It emphasizes rigor and exploration of the primary scientific literature to focus and cultivate student interest. The use of publicly-accessible literature databases, (eg., the National Library of Medicine's PubMed, and Google Scholar) is introduced.

Wolbachia Rodeo. The Wolbachia Rodeo is a hands-on classroom exercise that culminates in a day-long team-based competition by high school students from different schools. Each team collects and identifies common pest insects, notably mosquitoes and the red imported fire ant, Solenopsis invicta, macerates the insects, extracts and amplifies DNA using primers specific for the Wolbachia symbiotic insect bacterium, and then performs electrophoretic separation to identify the presence or absence of infection of the insect by Wolbachia. Positive samples are shared with the Microbes Within project, formerly at the Woods Hole Marine Biological Laboratory and now hosted by the Bordenstein laboratory at Vanderbilt University. Identified positive sequences are entered into a global Wolbachia database. The competitive nature of the culminating exercise dramatically engages student interest in the process of molecular research.

\section{FUNDING RECORD}

Throughout the 28-year history of Base Pair, support has been provided through varying combinations of private philanthropy, local and federal grants, agreements with the Mississippi Academy of Sciences, creation of an independent endowment fund, and institutional support from the JPSD and UMMC for faculty time, space, and resources. To date, external grant support for Base Pair activities has totaled over $\$ 2$ million $(\$ 2,043,970)$. That total does not include institutional support or the endowment fund. The greatest single component of that was provided by the Precollege Science Education Award program of the HHMI, which funded Base Pair continuously from 1994 through 2012. The non-profit Community Foundation of Mississippi has provided support for teacher professional development activities. Also not included in the total is an award of over \$1.25 million (2016-2021) from the NIGMS SEPA program for UMMC-based teacher professional development. While that award does not support Base Pair activities, it can be considered as a direct offshoot of the Base Pair program and thus continues to advance the science education development of Mississippi teachers. Institutional support is less amenable to quantitation, but includes UMMC faculty release time (232 current/former Base Pair students; each fulltime UMMC faculty mentor spends roughly 90 minutes each weekday during the school year with a Base Pair student, equaling 225 hours for two 15 week semesters/year, totaling roughly 52,200 faculty hours each year. This total does not include the fact that some mentors continue to work with students full time for 8-10 weeks during summers, or release time for a Murrah lead teacher (1 class period each weekday). The JPSD also provides bus service for Base Pair students to and from UMMC each weekday during the school year at no charge. The Mississippi Academy of Sciences continues to waive registration fees at their annual scientific meeting for Base Pair students. As elaborated below, this collaboration with Mississippi's premier science professional organization has played a pivotal role in supporting student research activities and advancement of a distinct science identity among high school students. In 2017, a private endowment fund was created for the Base Pair program through UMMC that continues to grow. In the eight years since the conclusion of external funding from HHMI, the continuation of Base Pair has rested on institutional buy-in by individual faculty, the administration of UMMC and JPSD, and the Mississippi Academy of Sciences. It is not unreasonable to identify the recognition of value gained, by individual students and for the educational system of Mississippi, as the coin that continues to maintain the program (Heisel, 2019). The scientific output of Base Pair students and their mentors is a tangible indicator of that value. A final example of recognition of value is the creation, in 2015, of a $\$ 250,000$ scholarship fund by the Kenan Foundation to help support Base Pair students 


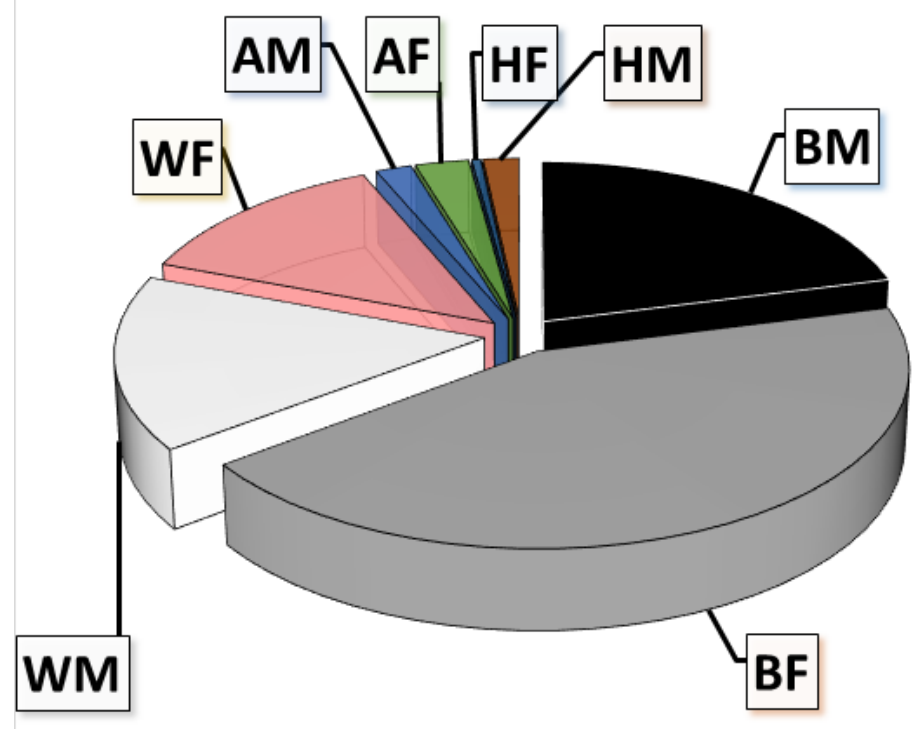

Figure 2. Demographic breakdown of Base Pair high school students by percentage of a total of 232 participants. Clockwise from top - BM, Black male; BF, Black female; WM, White male; WF, White female; AM, Asian male; AF, Asian female; HF; Hispanic female; HM, Hispanic male. As of $2019,95 \%$ of Murrah students are Black. The overall racial proportions of Base Pair are roughly similar to proportions at Murrah at the outset of the program in 1992.

who wish to attend Millsaps College, a private liberal arts institution in Jackson, Mississippi.

\section{PROGRAM OUTCOMES}

Student Research Mentorship. A total of 232 students have enrolled in this component; 220 have graduated and 12 remain to complete their tenure. Base Pair students have a $100 \%$ high school graduation rate. This compares favorably with the graduation rate for the JPSD overall (74\%), for Mississippi (84\%), and nationally (88\%). The college entry rate is estimated to exceed $99 \%$ (vs. $73 \%$ for Mississippi overall), with only a single student verified to not have progressed. Demographically, $40 \%$ of the students are male, $60 \%$ are female. The self-identified racial designations are shown in Figure 2.

As of the most recent assessment in May, 2019, of those students who are known to have completed baccalaureate education, greater than $63 \%$ have progressed to some form of post-baccalaureate training, and a total of 84 are known to have received advanced degrees (MD/DVM/PharmD, 26; PhD, 15; JD, 8 and a Master's degree, 35). Base Pair students have authored/presented over 425 scientific documents (Figure 3). Most have been published as abstracts, 20 as complete manuscripts in a peer-reviewed journal.

Teacher Professional Development. As shown also in Figure 3, Base Pair-trained teachers have published at least

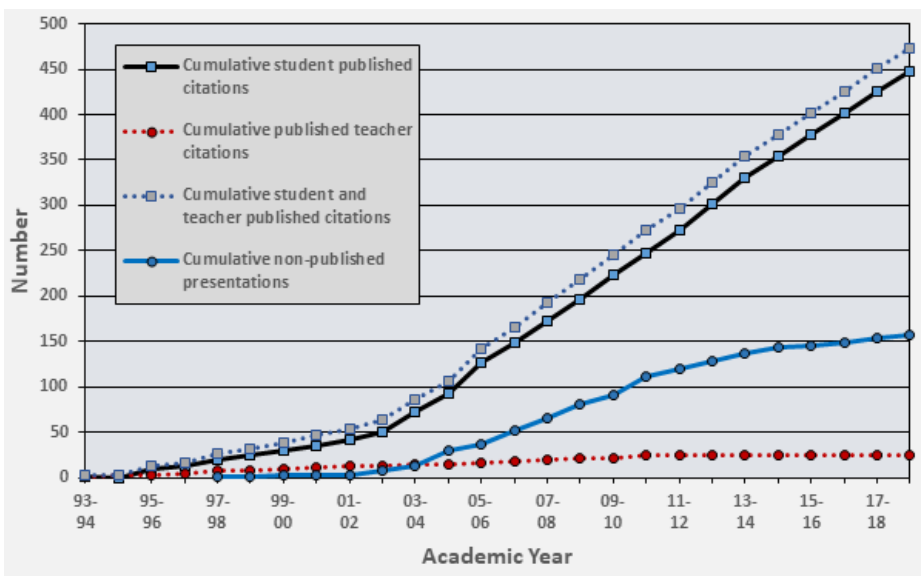

Figure 3. The cumulative growth rates for published citations (abstracts and peer-reviewed publications) by Base Pair students and teachers, and non-published presentations (workshops and training events) by Base Pair teachers.

25 scientific abstracts and delivered over 150 formal workshops or presentations in formal educational forums. In addition, our teachers self-report having submitted at least 159 grant applications for external funding, of which 124 have been funded, a $78 \%$ success rate. At least $\$ 580,000$ has been received by teachers through these grants. Demographically, over $90 \%$ of teachers have been female, and a slight majority have been Caucasian.

SOAR Program. The SOAR program at Jim Hill High School has graduated approximately 2,000 students since its inception in 2001. Each SOAR student is expected to complete and present a science fair project and many of these are subsequently submitted at regional (Mississippi Region II), state and international science fair venues. Figure 4 shows the results of these submissions for the region and state.

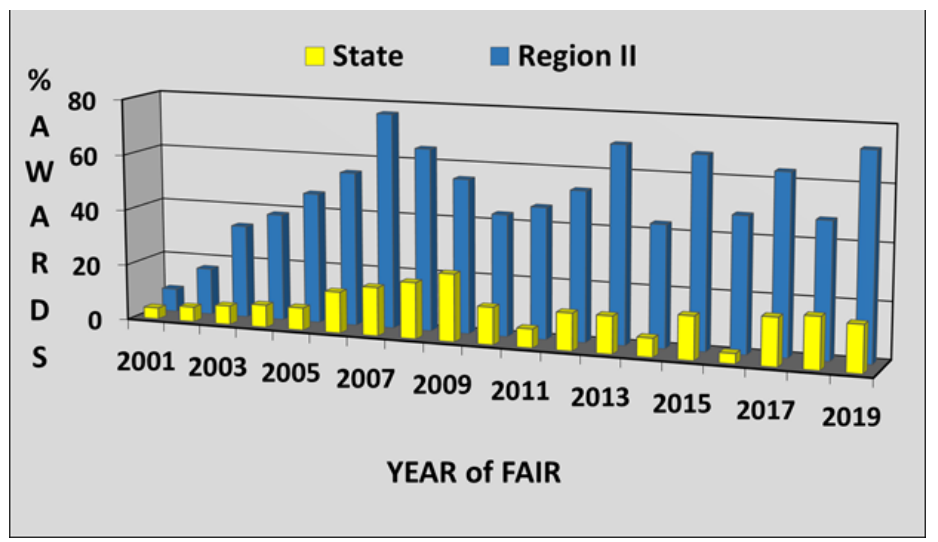

Figure 4. Science fair awards for projects by SOAR students from Jim Hill High School in the JPSD. The foremost tier represents the percentage of total awards (\% Awards) given each year at the annual Mississippi state science fair that were awarded to Jim Hill High School SOAR students. The rearmost tier shows a similar tabulation for results from the central Mississippi Region II science fair. 
From 2001 through 2019, SOAR students have received over $50 \%$ of all awards presented at the Jackson, Mississippi, Metro Area Region II science fair competition over that 18 year period. This is the largest regional competition in the state and involves students from schools in three central Mississippi counties.

RBI. The RBI curriculum has been implemented in four separate rural high schools - in Puckett, Terry, Morton, and Raleigh High Schools. With the exception of the most recent implementation in academic year 2019-2020 at Raleigh High School, the implementation of the curriculum has been associated improvements of the school's academic rating by the Mississippi Department of Education by at least one letter grade (A-F grading scale).

Wolbachia Rodeo. A total of nine Wolbachia Rodeo events have been conducted with over 170 students participating. These have been held variously at a high school, and on the campuses of two community colleges and a four-year liberal arts college.

Teacher Community. A significant result of Base Pair interactions has been the creation of an informal community of health learners in which public and private high school teachers communicate and interact with one another, with UMMC faculty, and increasingly with faculty from other Mississippi institutions of higher learning, notably the University of Mississippi and the University of Southern Mississippi. Information, ideas and sharing or resources characterize this community. This community was pivotal to receipt of a \$1.1 million SEPA award from the NIGMS for an expanded teacher professional development project by UMMC.

\section{CHALLENGES AND BARRIERS}

Overall, the Base Pair program has been successful in producing significant outcomes and in maintaining its longevity, despite continuing challenges. Perhaps the single greatest challenge over the 28 -year history has been that of turnover in the personnel of our high school partners. As one example, the JPSD has had a total of 10 Superintendents, including Interim Superintendents, during the tenure of Base Pair. Murrah High School has had six Principals. Fortunately, the position of Base Pair Lead Teacher at Murrah has been more stable, with only four such individuals. Maintaining continuity of the program has required considerable effort to establish, maintain, and reestablish new relationships at the school and district level. However, the benefits provided to the students served by Base Pair and recognition by parents of those benefits have helped to overcome those challenges. Institutional recognition of the service of UMMC faculty as
Base Pair mentors has also been greatly beneficial, a recognition that has endured through the tenure of five UMMC Chief Executive Officers, including one who served as a Base Pair mentor herself.

The second major challenge has been and continues to be tracking individuals who have participated in the program. In the absence of a definitive national database, it is particularly difficult and time-consuming to follow student progression after high school. However, it is equally challenging to maintain updated records on teachers, who experience frequent transfers across schools and districts and/or retire from teaching.

Funding a program like Base Pair is always a challenge, but the program has enjoyed a high level of in-kind support from UMMC. Chairs of the departments in which mentors have appointments have been most generous in allowing faculty to participate in training of high school students. Mentors are selected from faculty who have active research programs and are generally adequately funded. Despite the absence of external funding since 2012, it has only rarely been necessary to provide mentors with additional funding to support the students in the laboratory. Providing resources to support student travel to and participation in scientific venues, including costs for presentation materials, registration and abstract fees, and travel remains as an ongoing challenge.

\section{ELEMENTS PROMOTING SUSTAINABILITY}

The longevity of Base Pair can be attributed to several interrelated factors. The presence of a clear need for improved secondary school science education was and is recognized by campus leaders at UMMC and the JPSD. That need is similarly recognized by parents, who maintain advocacy for its continuation. In addition to serving as the impetus for creation of Base Pair, the willingness of these two institutions to facilitate the program activities must be considered essential. The ability to gain significant external funding from the HHMI allowed the program to gain a firm foundation and establish a positive local, state, and national reputation for excellence. Continuation of the program in the absence of that funding is in large part a result of the institutional, parental, and student recognition of the value added to the high school experience. The HHMI period also established protocols for training, communication, and delivery of services between the two institutions that do not require significant direct expenditures. The JPSD does provide transportation service for students to and from UMMC, as well as to the annual Mississippi Academy of Sciences meetings. Both UMMC and the JPSD allow faculty to oversee training of Base Pair students, which is both very positive and essential for program sustainability. However, the structure within which the training occurs has been coordinated to be consistent with 
routine expectations for faculty research/teaching efforts. At the academic health science center level, Base Pair students typically are immersed in and become a productive component of a faculty member's research team and expected research effort, as evidenced by the research citation record of Base Pair students and faculty. Beyond this contribution to the scientific literature, benefits have been harder to quantify. However, it is significant that five Base Pair graduates have become faculty members at UMMC, including one who now serves as Assistant Dean for Admissions for the UMMC School of Medicine. At the high school level, creation of a unique and state-accredited course for Base Pair brings the time and effort of the Murrah lead teacher within the scope of expectations for that faculty position. The association with the state academy of sciences has played a vital role in that citation record, in part by defraying the registration fees of Base Pair students who present at the annual meeting. Those experiences, and the contacts with faculty from undergraduate institutions across the state, often lead to scholarship offers and admission recognition for Base Pair students. This result is echoed by the results of others (Estrada et al., 2018).

The experience of Base Pair suggests that the sustainability of outreach programs in STEMM can be attributed primarily to four factors. The first of these is the environment in which the program is implemented. Specifically, do institutional leaders recognize and value the opportunity to engage in innovative relationships among different organizations that not only address mutually institutional missions, but also address greater community/societal needs (i.e., demonstrated need)? The engagement of institutional leadership has proven to be critical to a second factor, which is the institutionalization of the program. In the case of Base Pair, that institutionalization is the explicit incorporation of Base Pair within the high school curriculum and recognition by the state Department of Education. This assists with recruitment and tracking of students, facilitates lines of communication across institutions and with parents, and advances recognition by higher education admissions officers. A third factor is the presence of institutional champions at the faculty level, both at UMMC and in the high schools. Base Pair could not have succeeded, and cannot continue, without the dedication, attention, and sacrifice of faculty mentors. These individuals appreciate the value of outreach and support of future scientists/health care providers and continue to devote time, energy and research support to these young students. A core cadre of exceptional high school teachers must also be considered as institutional champions. Their efforts to excite students and develop interactive curricula that introduce students to possibilities not always recognized at the secondary school level has absolutely contributed to the success of the program. A final, and absolutely essential, factor is the degree to which the programs can provide tangible evi- dence of student progression (i.e., accrued benefit). To this end, the entrance of students into the professional scientific community, as evidenced by highly visible, professionally organized venues such as large scale science fair competitions and professional scientific forums, is a clear signal of that progression that parents, community members, admissions officers, and scholarship providers (and funders) readily recognize. The inclusion of professional scientific organizations, such as state academies of science or professional scientific societies, can be vital contributors to the perceived quality of that signal.

\section{CONCLUSION}

Mentorship and early introduction to the practice of science in professional settings is a proven means of encouraging further advancement into STEM/STEMM careers (e.g. Kitchen et al., 2006; McKendall et al., 2014; Tai et al., 2006; Winkleby, 2007). The willingness of biomedical research professionals at an academic health sciences center to formally partner with, and mentor, students and teachers at a major public school system, has demonstrated sustainability and success. Carlone and Johnson (2007) identified, through an explicit study of women of color in the sciences, three categories that define a strong science identity: 1) competence, 2) performance, and 3) recognition. Individuals need to be competent or able to demonstrate skills and science knowledge. Competence can be defined as an individual feeling confident that she/he has (or is capable of acquiring) the knowledge necessary to understand science concepts; performance as confidence in the ability to showcase science skills in public settings; and recognition as perception that others within the scientific community validate that competence and performance (McDonald et al., 2019). Base Pair students demonstrate both competence and performance criteria, to UMMC mentors and the broader scientific community through public presentations of their research. For both Base Pair students and teachers, the publications and abstracts, particularly those in the journal of the state academy of sciences (Journal of the Mississippi Academy of Sciences), can be considered as peer-reviewed acceptance of the quality of the program. Similarly, the success of our teachers in achieving external funding meets that benchmark. These clearly demonstrate recognition by greater scientific and professional educational communities. While not specifically measured by an instrument, the three benchmarks for possession of a scientific identity are evident as an outcome of the Base Pair program. These criteria, and the Base Pair model, also meet the three key processes of the tripartite model recognizes. Again, these are: compliance with research norms and rules (Base Pair students performing as functional members of UMMC research teams); identification with a professional group (through presentation/ 
publication of their work in professional scientific forums); and internalization and sharing of group values (through laboratory team discussions and interaction with fellow Base Pair students). It should be noted further that collaborations using professional settings, for example, a state academy of sciences, to demonstrate efficacy of a program provide credible venues that inculcate valid science identities to the participants. Such collaborations should be considered in any similar program development.

\section{AUTHOR INFORMATION Corresponding Author}

Rob Rockhold, PhD, Deputy Chief Academic Officer, University of Mississippi Medical Center, 2500 North State St., Jackson, MS 39216-4505. (601) 984-2810.rrockhold@, umc.edu

\section{Author Contributions}

The manuscript was written through contributions of all authors. All authors have given approval to the final version of the manuscript.

\section{ACKNOWLEDGMENTS}

Supported by the Base Pair Development Fund and a UMMC Faculty Incentive account to R. Rockhold. We recognize and appreciate the continued collaboration with the Mississippi Academy of Sciences and local supporters including the Community Foundation of Mississippi.

\section{FUNDING SOURCES}

The pivotal support of the Precollege Science Education Program of the Howard Hughes Medical Institute is gratefully acknowledged. Dr. Rockhold is currently supported by an award from the National Institute of General Medical Sciences of the National Institutes of Health under Award Number R25GM129212. The content is solely the responsibility of the authors and does not necessarily represent the official views of the National Institutes of Health.

\section{ABBREVIATIONS}

AP: Advanced Placement; APAC: Academic and Performing Arts Complex; CRLA: College Laboratory Research Apprenticeship; HHMI: Howard Hughes Medical Institute; HSSRLA: High School Summer Research Laboratory Apprenticeships; KHEP: K-12 Higher Education Partnership; JPSD: Jackson Public School District; PCR: Polymerase Chain Reaction; RBI: Rural Biomedical Initiative; SOAR: Student Oriented Academic Research; STEMM: Science, Technology, Engineering, Mathematics, and Medicine; MMMC: University of Mississippi Medical Center

\section{REFERENCES}

Adams, R.G., Dellinger, T., Kuhn, M., Streckfus, C., and Bigler, L. (2001). p53 as a diagnostic tool for the detection of cancer and its role in tumor progression. Journal of the Mississippi Academy of Sciences, 46(4), 163-167. https://msacad.org/ journal/oct01journal/oct.pdf. Accessed September 22, 2020.

Bradley Phillips, T. (2014). Brookhaven Students' experiment at space station. Retrieved from https://www.clarionledger. com/story/news/2014/07/17/brookhaven-studentsexperiment-space-station/12820943/. Accessed July 18, 2020.

Carlone, H.B., and Johnson, A. (2007). Understanding the science experiences of successful women of color: Science identity as an analytic lens. Journal of Research in Science Teaching, 44(8), 1187-1218.

Estrada, M., Hernandez, P.R., and Schultz, P.W. (2018). A longitudinal study of how quality mentorship and research experience integrate underrepresented minorities into STEM careers. CBE Life Sciences Education, 17, ar9.

Estrada, M., Woodcock, A., Hernandez, P.R., and Schultz, P.W. (2011). Toward a model of social influence that explains minority student integration into the scientific community. Journal of Educational Psychology, 103(1), 206-222.

Fayer, S., Lacey, A., and Watson, A. (2017). STEM Occupations: Past, Present, and Future. U.S. Bureau of Labor Statistics, 21. https://www.bls.gov/spotlight/2017/science-technology-engineering-and-mathematics-stem-occupations-past-present-and-future/home.htm. Accessed August 11, 2020.

Findley-Van Nostrand, D., and Pollenz, R.S. (2017). Evaluating psychosocial mechanisms underlying STEM persistence in undergraduates: Evidence of impact from a six-day pre-college engagement STEM academy program. CBE Life Sciences Education, 16(2), ar36. https://doi.org/10.1187/ cbe.16-10-0294

Heisel, A. (2019). UMMC empowering through Base Pair. Jackson Free Press, 17(19), 14.

Hernandez, P.R., Hopkins, P.D., Masters, K., Holland, L., Mei, B.M., Richards-Babb, M., Quedado, K., and Shook, N.J. (2018). Student integration into STEM careers and culture: A longitudinal examination of summer faculty mentors and project ownership. CBE-Life Sciences Education. 17, ar50, $1-14$.

Hudson, P. (2004). Specific mentoring: a theory and model for developing primary science teaching practices. European Journal of Teacher Education, 27(2), 129-146.

Kitchen, J.A., Sonnert, G., and Sadler, P.M. (2018). The impact of college- and university-run high school summer programs on students' end of high school STEM career aspirations. Science Education, 102(3), 529-547.

McDonald, M.M., Zeigler-Hill, V., Vrabel, J.K. and Escobar, M. (2019). A Single-item measure for assessing STEM identity. Frontiers in Education, 26 July. https:/www.frontiersin.org/ articles/10.3389/feduc.2019.00078/full. Accessed September 21, 2020. 
McKendall, S.B., Kasten, K., Hanks, S., and Chester, A. (2014). The Health Sciences and Technology Academy: An educational pipeline to address health care disparities in West Virginia. Academic Medicine, 89(1), 37-42.

Mississippi Department of Education. Mississippi State Report Card 2018-2019. Retrieved from https://msrc.mdek12.org/ downloads/2018/Summary/Summary_0000-000_2018. pdf. Accessed May 25, 2020.

Mississippi Institutes of Higher Learning. Degree Awarded Academic Years 2015-2019. https://public.tableau.com/views/ Degree_Awarded/Dashboard1. Accessed July 5, 2020.

National Science Board. (2015). Revisiting the STEM workforce: A companion to science and engineering indicators 2014. Retrieved from https://www.nsf.gov/publications/ pub_summ.jsp?ods_key=nsb201510. Accessed August $22, \overline{2} 020$.

State Indicators - S\&E Indicators | NSF - National Science Foundation. Retrieved from https://ncses.nsf.gov/indicators/ states/. Accessed June 29, 2020.

Summers, R.L., Anders, R.M., Woodward, L.H., Jenkins, A.K., and Galli, R.L. Effect of routine pulse oximetry measurements on emergency department triage classification. American Journal of Emergency Medicine 16, 5-7, 1998. 